\title{
TRÁFICO DE MULHERES BRASILEIRAS PARA FINS DE EXPLORAÇÃO SEXUAL EM PORTUGAL E INTERSECCIONALIDADE: UM ESTUDO DE CASO
}

\author{
Sofia Neves ${ }^{1}$
}

Resumo: Este artigo discute o fenómeno do tráfico de mulheres para fins de exploração sexual, usando como referência a teoria da interseccionalidade. A partir de um estudo de caso, analisam-se as vivências de uma mulher brasileira vítima de tráfico de seres humanos. As evidências encontradas neste estudo clarificam os dados apontados na literatura no que respeita à associação entre condições estruturais de desigualdade social e vulnerabilidade ao tráfico para fins de exploração sexual.

Palavras-chave: tráfico de mulheres, exploração sexual, interseccionalidade

Trafficking of Brazilian women for sexual exploitation in Portugal and Intersectionality: A case study (Abstract): This paper discusses the phenomenon of trafficking of women for sexual exploitation, using as reference the intersectionality theory. Based on a case study, we analyze the experiences of a Brazilian woman victim of human trafficking. The evidences found in this study clarify what the literature points out as the association between social structural conditions of inequality and vulnerability to trafficking for sexual exploitation

Keywords: women trafficking, sexual exploitation, intersectionality theory

\section{Introdução}

O crescente trânsito de pessoas e de bens, fruto das políticas de livre circulação, embora constitua um ganho civilizacional importante, tem vindo a acentuar as desigualdades sociais, a fomentar as assimetrias no acesso às oportunidades laborais e a reforçar a precariedade das condições de trabalho (Miko, 2003), especialmente entre as mulheres (United Nations Develop-

\footnotetext{
${ }^{1}$ Instituto Superior da Maia (ISMAI), Maia, Portugal

PSICOLOGIA, Vol. XXIV (2), 2010, Edições Colibri, Lisboa, pp. 177-196
} 
ment Programme - UNDP, 2006). Algumas formas de exclusão no feminino têm sido, nos últimos anos, fortemente condicionadas pela feminização das migrações (Miranda, 2009), um processo cada vez mais evidente, quer na Europa, quer no resto do mundo, e que se constitui como uma das características mais marcantes da era actual das migrações (Castles \& Miller, 2003). Ainda que a violência e a discriminação de género possam não ser o resultado directo da feminização das migrações, o aproveitamento deste processo por parte de quem se envolve activamente na exploração de mulheres socialmente vulneráveis tem tido como consequência um aumento substancial da vitimação feminina.

O tráfico de mulheres para fins de exploração sexual, sendo uma das formas de opressão feminina que melhor espelha os efeitos da feminização das migrações, tem vindo a ser estudado a partir de uma análise de género (Raymond, 2002; Conselho da Europa, 2005), mas cada vez mais com base numa grelha teórica interseccional (Schecter, 1998). O tráfico de seres humanos, especialmente o que envolve exploração sexual, reveste-se de particularidades muito específicas, de entre as quais se destacam as especificidades de género, de classe e de pertença étnica (Neves, 2010). A instituição do trabalho feminino forçado, no decurso das migrações, reflecte relações sociais de género e de classe desequilibradas e assentes numa distribuição não equitativa de poder entre homens e mulheres (Moghadam, 1999; Nolin, 2006). Não existindo num vazio social, o género emerge e constitui-se no âmago de matrizes sociais nutridas por relações estreitas entre as questões da etnicidade, da cultura e da classe (Hondagneu-Sotelo, 2005). As dinâmicas dos processos de migração não são aleatórias, nem biologicamente determinadas, estando antes dependentes de condições sócio-demográficas como a etnia, o sexo, a classe social e a idade, assim como de outras condições como o nível educacional, a ocupação, o estatuto conjugal e as pressões políticas e económicas associadas a zonas geográficas particulares (O.McKee, 2000).

Os dados do Relatório Anual sobre Tráfico de Seres Humanos, de 2009, produzido pelo Ministério da Administração Interna, confirmam a tendência global. O tráfico para fins de exploração sexual tende a materializar-se quando se intersectam determinadas pertenças identitárias. A pertença sexual, aliada à pertença étnica e de classe, é um factor de risco para o envolvimento em situações de exploração sexual. Assim, constata-se que as vítimas de tráfico para fins de exploração sexual são sobretudo mulheres estrangeiras, com idades compreendidas entre os 20 e os 30 anos, que provêm de países com nítidos contrastes sociais, onde as taxas de pobreza e de precariedade social são muito elevadas.

A discriminação interseccional é o produto das posições de marginalização que as mulheres migrantes são forçadas a assumir, sendo crucial anali- 
sar-se o modo como estas múltiplas pertenças determinam a vulnerabilidade à vitimação (Crenshaw, 1991), nomeadamente à vitimação sexual.

Enunciaremos de seguida os contributos da teoria da interseccionalidade para o estudo das migrações e do tráfico de mulheres para fins de exploração sexual.

\section{Interseccionalidade, migrações femininas e tráfico de mulheres para fins de exploração sexual}

A consciência internacional face aos diferentes rostos que a discriminação pode apresentar começou a despontar na Primeira Conferência Mundial sobre as Mulheres, organizada em 1975, cimentando-se verdadeiramente 20 anos depois em Beijing, com a realização da Quarta Conferência Mundial sobre as Mulheres (Pittaway \& Bartolomei, 2001). As recomendações produzidas no âmbito deste último evento exortaram a indispensabilidade de se reconhecer a importância da idade, da deficiência, da posição socioeconómica e da pertença a um determinado grupo étnico ou racial na análise da discriminação de género. O pressuposto da interseccionalidade começava então a afirmar-se, determinando assim a necessidade de se contemplarem as diversas pertenças identitárias na compreensão das situações de desigualdade social.

Tendo surgido, enquanto formulação teórica, no âmbito dos estudos feministas nórdicos, a teoria da interseccionalidade é hoje porventura a abordagem multidisciplinar mais importante da teorização feminista e anti-racista no que respeita à análise da opressão (Nash, 2008). Claramente influenciada pelos feminismos negros e pelas teorias pós-coloniais, a teoria da interseccionalidade resgata a reflexão sobre o impacto das hierarquias sociais e culturais de género e de classe.

Cunhado por Kimberlé Crenshaw, durante a década de 90 do século XX, o termo interseccionalidade pretende firmar a relação de interacção e de interdependência que se estabelece entre algumas categorias identitárias potencialmente vulnerabilizantes. A autora, uma teórica da área legal, publicou dois textos fundamentais, Demarginalizing the intersection of race and sex: A black feminist critique of antidiscrimination doctrine, feminist theory and antiracist politics e Mapping the margins: Intersectionality, identity, politics and violence against women of color, em 1989 e em 1991 respectivamente, no âmbito dos quais salientava a incapacidade da lei para tornar visíveis as experiências de discriminação das mulheres negras, argumentando que a discriminação sofrida por este grupo era de natureza interseccional (Berger \& Guidroz, 2009). 
$\mathrm{Na}$ tentativa de encontrar similitudes e pontos de encontro entre os movimentos anti-racistas e os estudos feministas (que nem sempre equacionaram a discriminação a partir de uma concepção racial), Crenshaw propôs uma matriz de análise das relações sociais que não se limitasse a considerar a multiplicação das categorias identitárias. A proposta da autora parte de uma base estrutural e dinâmica, sendo a interseccionalidade não a justaposição de tipos de discriminação, mas antes a interacção desses elementos.

A noção de interacção entre formas de subordinação, segundo Piscitelli (2008), permite transpor a ideia de “(...) sobreposição de opressões. Por exemplo, a ideia de que uma mulher negra é duplamente oprimida, à opressão por ser mulher deve ser adicionada a opressão por ser negra" (p. 6). Não se trata de somar diferentes modalidades de discriminação, mas de compreender como elas se intersectam.

Assim, a teoria da interseccionalidade pretende examinar como as diversas categorias identitárias interagem a múltiplos níveis para se manifestarem em termos de desigualdade social. Os modelos clássicos de compreensão dos fenómenos de opressão, como os baseados no sexo/género, na raça/etnicidade, na classe, na religião, na nacionalidade, na orientação sexual ou na deficiência, não agem de forma independente uns dos outros, interrelacionando-se e criando um sistema que reflecte a intersecção de múltiplas formas de discriminação (Nogueira, em publicação).

A discriminação interseccional afecta especialmente as mulheres. A opressão feminina, fruto da raça/etnia, religião, casta, nacionalidade e de outras categorias sociopolíticas, é agravada pela discriminação de género. Como resultado, as mulheres, mais do que os homens, são sujeitas a múltiplas formas de violação dos direitos humanos (Pittaway \& Bartolomei, 2001). Como Judith Butler admitiu, em 1990, o género intersecta outras identidades constituídas discursivamente, como a raça, a classe e a sexualidade, o que torna impossível separar o género das intersecções políticas e culturais no domínio das quais o género se produz e é mantido.

Nessa óptica, e segundo Nogueira (em publicação), a experiência interseccional é maior do que a soma do racismo e do sexismo. A interseccionalidade enfatiza por isso a multidimensionalidade das experiências vividas dos sujeitos marginalizados, salientando que propostas de análise da identidade como camadas removíveis e separadas redundam em generalizações abusivas (Nogueira, em publicação). Como salienta Crenshaw, em 2002,

'A discriminação interseccional é particularmente difícil de ser identificada em contextos onde forças económicas, culturais e sociais silenciosamente moldam o pano de fundo, de forma a colocar as mulheres em uma posição onde acabam sendo afetadas por outros sistemas de subordinação. Por ser tão comum, a ponto de parecer um facto da vida, natural ou pelo menos imutável, esse pano de fundo (estrutural) é, muitas vezes, invisível. O efeito disso é que 
somente o aspecto mais imediato da discriminação é percebido, enquanto que a estrutura que coloca as mulheres na posição de "receber" tal subordinação permanece obscurecida (p. 176).

Crenshaw observou as dinâmicas da interseccionalidade estrutural sobretudo no trabalho que desenvolveu em casas de acolhimento situadas em comunidades pobres de Los Angeles, com mulheres vítimas de violência na intimidade (Crenshaw, 1991). Na maioria dos casos, a violência física que levou estas mulheres a procurar apoio nas referidas casas de acolhimento, era a manifestação mais imediata das suas vivências de subordinação. Muitas destas mulheres estavam desempregadas ou tinham empregos precários e eram pobres. À experiência da violência perpetrada pelos companheiros somavam-se outras experiências de vulnerabilidade, de igual gravidade, contribuindo esta interacção para uma situação de elevado risco social.

$\mathrm{O}$ risco social acentua-se quando a estas experiências se adicionam outras pertenças identitárias específicas. As mulheres migrantes são particularmente vulneráveis à discriminação (Crenshaw, 1991). As migrações trazem consigo experiências de discriminação interseccional, na medida em que as mulheres migrantes são afectadas pelas suas múltiplas pertenças identitárias, encerrando estas o somatório de diferentes formas de opressão.

Como salienta Machado, em 2005, “(...) a coisificação do migrante permite a exploração radical a que estão sujeitos, tanto no país de origem, antes do ato de emigrar, como no país de recepção, após a entrada na nova sociedade" (p. 5). A migração pode ser, pois, um continuum de experiências de discriminação, não só no país de origem, mas também no país receptor. $\mathrm{Na}$ verdade, as realidades sociais recentes (ou pelo menos de apreciação mais recente) convidam-nos a reconhecer a importância da interseccionalidade nos estudos migratórios. Ao assumir que a raça/etnicidade, a classe e o género são processos culturalmente definidos, a teoria da interseccionalidade reconhece que as posições sociais ocupadas por cada um/a influem na decisão de permanecer ou não no país de origem, na decisão de migrar ou não migrar. A observação das inter-influências a que as migrantes estão sujeitas, não só permite compreender como as estruturas sociais condicionam as decisões migratórias, mas também como é produzida a praxis dessas decisões (Collins, 2005).

A segregação de género nas estatísticas e na pesquisa sobre migrações deve dar lugar a uma observação atenta e rigorosa das especificidades de género, mas também de outras pertenças identitárias. Trabalhar com múltiplas categorias de pertença é, como defende Piscitelli (2008), dispor de ferramentas analíticas para apreender a associação de múltiplas diferenças e desigualdades: “(...) não se trata apenas de observar a diferença sexual, nem a relação entre género e etnia/raça ou género e sexualidade, mas da diferença, em sentido amplo, para dar cabida às interações entre possíveis diferen- 
ças presentes em contextos específicos" (Piscitelli, 2008, p. 266). Os sistemas de opressão sobrepõem-se e cruzam-se, criando intersecções complexas nas quais dois, três ou quatro eixos se tocam (Crenshaw, 2002).

É recorrente, na literatura, a comparação das diferenças existentes entre homens e mulheres migrantes, não sendo essas diferenças problematizadas com o intuito de se sistematizar o que as constrói, as condiciona ou as mantém. Parte-se igualmente do princípio de que as experiências das mulheres são homogéneas entre si, assim como as experiências dos homens, não se assumindo que existem diferentes grupos de mulheres e de homens e que as especificidades desses diferentes grupos ocasionam diferentes experiências de subordinação.

Por outro lado, os estudos migratórios têm privilegiado os factores económicos na explicação da decisão de migrar (Lee 1965; Ritchey 1976, cit. in Brooks \& Redlin, 2009), esquecendo que a questão económica é apenas parte do problema e não $o$ problema.

As leituras insuficientes e inquinadas de um fenómeno que é, na sua natureza, multideterminado, estreitam a visão compreensiva que é necessário desenvolver sobre as mais diversas formas de injustiça social. Qualquer análise que não tome a interseccionalidade em conta, falha na observação de como a subordinação opera (Nogueira, em publicação). Como recorda Crenshaw, em 2002,

As mulheres racializadas freqüentemente estão posicionadas em um espaço onde o racismo ou a xenofobia, a classe e o gênero se encontram. Por conseqüência, estão sujeitas a serem atingidas pelo intenso fluxo de tráfego em todas essas vias. As mulheres racializadas e outros grupos marcados por múltiplas opressões, posicionados nessas intersecções em virtude de suas identidades específicas, devem negociar o "tráfego" que flui através dos cruzamentos. Esta se torna uma tarefa bastante perigosa quando o fluxo vem simultaneamente de várias direções (p. 177).

O tráfico de mulheres para fins de exploração sexual, assim como os processos migratórios, poderá traduzir (e traduz muitas vezes) uma forma de discriminação interseccional. As vítimas são, como sublinha Crenshaw (2002), oriundas de grupos marcados por múltiplas opressões. Como sugerem Peixoto e colaboradores/as (2005), "o tráfico deve entender-se no contexto das migrações, e, nesse sentido, deveremos procurar a explicação para o seu surgimento e expansão nas teorias tradicionais das migrações" (p. 30).

Todas as estimativas apontam para o facto das mulheres e das crianças de sexo feminino serem as principais vítimas deste tipo particular de tráfico, o que também se deve, em grande medida, à crescente feminização da pobreza. Mas o tráfico não é meramente o resultado de relações sociais de género hierarquizadas (Langevin \& Belleau, 2000). Por tráfico de mulheres entende-se um amplo conjunto de situações de exploração baseadoa no 
desequilíbrio de poder entre as partes: as vítimas e os traficantes. Este desequilíbrio pode caracterizar-se por desigualdade de género, desigualdade étnica, desigualdade económica, desigualdade etária, entre outras manifestações de desigualdade (Langevin \& Belleau, 2000).

A discriminação de género sofrida nos países de origem, especialmente no que respeita ao acesso ao emprego, torna as mulheres mais susceptíveis à exploração sexual, sendo esta muitas vezes promovida por outras mulheres (Carling, 2006). A oportunidade das mulheres migrarem em condições regulares, estando limitada pelas suas parcas qualificações académicas e pelos seus diminutos recursos económicos, leva-as a aceitar mais facilmente as falsas promessas dos/as angariadores/as e a migrar clandestinamente (Banda \& Chinkin, 2004). Em contextos social e economicamente desfavorecidos, o baixo estatuto das mulheres e a persistente violação dos seus direitos, são factores de risco para o seu envolvimento em práticas sexuais forçadas. A obstrução à escolarização e à educação das meninas, a vinculação do papel das mulheres a responsabilidades domésticas e familiares e o impedimento destas à participação política e à vivência da sua sexualidade plena faz com que a desigualdade de género seja reforçada e legitimada (Global Alliance Against Traffic in Women, 2000).

A vulnerabilidade ao tráfico parece estar também dependente da subordinação étnica ou racial, sendo alguns grupos frequentemente mais visados do que outros. Uma vez nos países receptores, as vítimas continuam a sofrer os efeitos dessa subordinação, já que a ilegalidade as remete, ou para a invisibilidade, ou para a visibilidade distorcida. Muitas vezes tratadas pelas populações dos países receptores como estrangeiras e prostitutas, as vítimas de tráfico resistem em pedir ajuda e são frequentemente privadas dos seus direitos fundamentais (como o direito à assistência médica) (Banda \& Chinkin, 2004).

A usual confusão entre tráfico e prostituição motiva que muitas vítimas permaneçam na obscuridade e não sejam devidamente apoiadas. Se estas mulheres tiverem nacionalidades conotadas com o trabalho sexual, a indiferença social é ainda mais evidente. As vítimas brasileiras são especialmente negligenciadas em termos de protecção social. Ao assumir-se que a nacionalidade brasileira é predominante na indústria do sexo em Portugal, toma-se a sua situação como uma opção "laboral migratória", o que faz com que passem despercebidas evidências de exploração e tráfico Santos et al., 2007). Mais ainda, a crença na naturalização da violência associada à prostituição, faz com que muitas vezes a violência seja legitimada, não só por quem a pratica mas também por quem dela é alvo.

As condições que levam as mulheres a ser vulneráveis ao tráfico para fins de exploração sexual, nomeadamente o desemprego e a precariedade social, dão lugar a outras, igualmente incapacitantes. 
A manutenção das situações de tráfico perpetua a noção de coisificação do/a migrante (Machado, 2005). "O tráfico não é uma esfera distante do universo da legalidade, restrito ao submundo do crime; o tráfico compartilha com a sociedade uma "inscrição simbólica" que permite a sua própria existência” (Machado, 2005, p. 14).

Mulheres brasileiras vitimas de tráfico para fins de exploração sexual em Portugal

De acordo com Santos e colaboradores/as (2007), em Portugal, o tráfico de mulheres para fins de exploração sexual atinge sobretudo vítimas de nacionalidade brasileira, seguindo-se as vítimas da Europa de Leste (especialmente as Romenas) e as Africanas (sobretudo Nigerianas). Este dado havia sido já aferido, em 2004, no âmbito da investigação $O$ Tráfico de Migrantes em Portugal: Perspectivas Sociológicas, Jurídicas e Políticas, coordenada por João Peixoto. Em ambos os estudos aponta-se o facto das redes de tráfico de mulheres oriundas do Brasil serem geralmente compostas por portugueses e brasileiros, de ambos os sexos, sendo as regiões de origem, quer dos/as angariadores/as, quer das vítimas, diversificadas. Os/as angariadores/as identificados/as neste estudo eram sobretudo da região do Nordeste, de São Paulo e do Rio de Janeiro. No caso das vítimas, mulheres entre os 20 e os 30 anos de idade, a sua região de origem é predominantemente o Nordeste brasileiro. As vítimas provinham de meios sociais desfavorecidos das regiões mais pobres do Brasil, muitas eram analfabetas ou tinham baixa escolaridade e algumas já exerciam a prostituição no seu país. Uma vez em Portugal eram obrigadas a exercer actividades sexuais, em situações de elevada precariedade e sob violência (ou ameaça de violência), destinando o pouco dinheiro que conseguiam amealhar às famílias, que geralmente permaneciam no país de origem. Para estas mulheres, a imigração é entendida como uma estratégia de sobrevivência, sendo a decisão de abandonar o país de origem motivada por razões económicas. A maior parte das mulheres traficadas quer regressar ao Brasil depois de concretizar os seus objectivos financeiros (Peixoto et al., 2005).

Segundo o Serviço de Estrangeiros e Fronteiras (SEF) o perfil da vítima de tráfico para fins de exploração sexual, em Portugal, pode ser descrito da seguinte forma:

"Mulher brasileira, com idade compreendida entre os 22 e os 30 anos, solteira, com nível médio de instrução (idêntico ao $12 .^{\circ}$ ano de escolaridade em Portugal) e emprego no sector terciário no pais de origem, oriunda maioritariamente do estado de Goiás, viajando pelos seus próprios meios e vontade para Portugal" (cit. in Santos et al., 2007, p. 229). 
As estatísticas nacionais e internacionais são igualmente inequívocas quanto à nacionalidade das vítimas. Durante o ano de 2009 foram sinalizadas em Portugal cerca de 84 vítimas de tráfico, sendo 61 mulheres, maioritariamente de nacionalidade brasileira (Ministério da Administração Interna, 2009).

As explicações para este facto são variadas. De um modo geral poder-se-á observar que o número expressivo de vítimas de tráfico para fins de exploração sexual de nacionalidade brasileira acompanha a crescente presença de imigrantes brasileiros/as, especialmente de mulheres, em Portugal.

Padilla (2006) salienta que os/as brasileiros/as procuram Portugal porque o associam à "velha pátria mãe" (p. 49). Os laços históricos, o idioma comum, o acesso a redes sociais de apoio, a presença de familiares ou conhecidos/as em Portugal, a proximidade cultural e a não necessidade de visto de entrada no país são factores de atracção que impulsionam fortemente a migração brasileira para Portugal. Embora a primeira vaga de imigrantes brasileiros/as (década de 80 e princípios da década de 90) fosse constituída maioritariamente por pessoas qualificadas (dentistas, informáticos/as e publicitários/as), as vagas mais recentes trazem a Portugal profissionais menos qualificados/as, o que limita substancialmente a sua inserção no mercado de trabalho e potencia a precariedade laboral. Verifica-se uma percentagem elevada de imigrantes brasileiros/as a trabalhar na indústria de hotelaria, na construção civil e em actividades domésticas (são as mulheres quem ocupa posições laborais menos diferenciadas) (Padilla, 2006). Mesmo os/as imigrantes com mais habilitações são inseridos/as em actividades que não fazem jus à sua formação, havendo um claro desajuste entre a qualificação desses/as imigrantes e os empregos que têm em Portugal (França, 2010).

Os fluxos migratórios desenvolvidos com o auxílio de traficantes parecem responder aos mesmos factores de repulsão no país de origem e de atracção nos países de destino que outros fluxos migratórios "simples" (Impe, 2000 cit. in Peixoto et al., 2005).

A precariedade económica dos países de origem e a promessa de maior dignidade social e laboral dos países receptores constituem-se como alavancas para a mobilidade das pessoas. A Pesquisa Nacional sobre o Tráfico de Mulheres, Crianças e Adolescentes para fins de Exploração Sexual Comercial do Brasil (PESTRAF) elabora frequentemente uma análise do tráfico de mulheres para fins de exploração sexual comercial com base em indicadores socioeconómicos (relações de mercado/consumo/projectos de desenvolvimento/trabalho e migração), tentando compreender e explicar como se conjugam os factores de repulsão com os factores de atracção. $\mathrm{O}$ que se tem verificado é que a relação entre os indicadores socioeconómicos em apreciação favorece as desigualdades sociais, de género, raça/etnia e 
geração e determina, em larga medida, a vulnerabilidade das mulheres brasileiras ao tráfico (Leal \& Leal, 2005).

As migrantes brasileiras são afectadas pela interacção das noções de sexualidade, género, raça, etnicidade e nacionalidade, como sugere Piscitelli (2008). As imagens sobre o Brasil e sobre as mulheres brasileiras, difundidas e representadas pela sociedade portuguesa, mas não só, são marcadas pela simbologia da sexualidade e corporalidade específica, no âmbito da qual as mulheres são apresentadas como erotizadas e pouco intelectualizadas (França, 2010). Como lembra Thaís França (2010),

"É dentro dessa lógica que se dá a subordinação à qual muitas brasileiras estão submetidas em Portugal. Para além de serem relegadas a ocupações mais precárias no mercado de trabalho português, com baixo prestígio social, baixa remuneração, horários estendidos e demais tipos de exploração, essas mulheres encontram-se presas dentro das imagens de alegres e festivas, sensuais e exóticas. Aqui, a experiência laboral exerce forte influência na forma como as identidades devem ser interpretadas, neste caso: um desfile de carnaval ininterrupto (p. 10).

A construção do comércio sexual no Brasil é apanágio de um processo histórico de desigualdades e injustiças, sobretudo para as mulheres, sendo que as contradições económicas e sociais vividas dentro do país favorecem a existência e a proliferação de redes nacionais e internacionais promotoras da prostituição e do tráfico de mulheres (Cavalcanti, s/d). O facto de o Brasil ter sido, nos últimos anos, incluído nos circuitos mundiais do turismo sexual, fez com que a representação social das mulheres brasileiras como prostitutas fosse reforçada (Piscitelli, 2004). Assim, no panorama global, a nacionalidade brasileira, mais do que a cor da pele, parece conferir às mulheres uma condição sexualizada (Piscitelli, 2007, 2008), sobretudo quando a esta se associa a condição de migrante:

"A ideia de que elas são portadoras de uma disposição naturalmente intensa para fazer sexo e uma propensão à prostituição, combinadas com noções ambíguas sobre seus estilos de feminilidade, tidos como submissos, com uma alegre disposição para a domesticidade e a maternidade, tende a atingir indiscriminadamente essas migrantes (Piscitelli, 2008, p. 269).

A construção do estereótipo da mulher brasileira assente na imagem de figura exótica e orientada para práticas sexuais a troco de dinheiro e com um estatuto jurídico de marginalidade é, assim, uma evidência incontornável em Portugal (Santos, 2005).

Não fornecendo a conjuntura social e o mercado brasileiro condições de sustentabilidade económica, muitas mulheres brasileiras optam por projectos migratórios, esperando a partir deles garantir a sua subsistência e a das suas famílias. Se em alguns casos a decisão de migrar é acompanhada da 
decisão de se prostituírem no país receptor, em outros casos a intenção não é a do envolvimento em actividades sexuais. Muitas mulheres brasileiras imigram esperando obter emprego na indústria hoteleira ou de restauração, domínio onde se encontram efectivamente a trabalhar.

Ainda que algumas mulheres saibam previamente que vão trabalhar na indústria do sexo ou como empregadas domésticas, desconhecem que no destino irão ser sujeitas a exploração laboral ou sexual, tendo que entregar aos "empregadores" quase tudo (muitas vezes tudo) o que ganham com o seu "trabalho". As vítimas de tráfico ficam habitualmente alojadas em lugares sem segurança, vivendo na clandestinidade e trabalhando ilegalmente (Cavalcanti, s/d).

É possível, assim, concluir que, na busca de melhores condições de vida, as mulheres brasileiras migrantes confrontam-se muitas vezes com novas experiências de discriminação interseccional. São vítimas de violência e de opressão pelo facto de serem mulheres, brasileiras, migrantes e pobres, assim como pelo facto de serem conotadas como prostitutas.

\section{Estudo de caso}

No âmbito de uma investigação qualitativa mais alargada sobre tráfico de mulheres para fins de exploração sexual em Portugal, elaborou-se um estudo de caso com uma mulher de nacionalidade brasileira. $\mathrm{O}$ estudo de caso é uma metodologia de investigação que procura recolher, de modo intensivo e profundo, informações acerca de uma pessoa, organização, situação ou local (Guerra, 2006). Assim, permite focar unidades sociais complexas a partir da observação e análise de realidades singulares, com vista à compreensão exaustiva dos fenómenos (VanWynsberghe \& Khan, 2007).

Este caso foi seleccionado pela sua intensidade (Flick, 2005, p. 71), representando o que tem vindo a ser descrito na literatura como um caso típico de tráfico de mulheres brasileiras para fins de exploração sexual em Portugal.

\section{Caracterização da participante}

Maria $^{2}$ é originária do Nordeste do Brasil, Goiás, e tem 21 anos de idade. Frequentou a escola até ao equivalente, em Portugal, ao 9. ${ }^{\circ}$ ano de escolaridade. Tem 8 irmãos mais velhos (todos rapazes) e provém de uma família de parcos recursos socioeconómicos, cuja subsistência está ligada à agricultura. Os pais de Maria são analfabetos e nenhum dos seus irmãos tem

\footnotetext{
${ }^{2}$ Nome fictício
} 
habilitações literárias superiores às suas. É divorciada e não tem filhos. Encontra-se em Portugal há cerca de um ano.

A Maria foi sinalizada como vítima de tráfico para fins de exploração sexual pelo $\mathrm{SEF}$, em consequência de uma acção de fiscalização a casas nocturnas na zona norte do país.

\section{Procedimentos, técnicas de recolha e tratamento dos dados}

Depois de obtido o consentimento informado, foi realizada uma entrevista semi-estruturada (Protocolo de entrevista para mulheres vítimas de tráfico para fins de exploração sexual, Neves, 2008) à Maria, com o propósito de recolher dados sobre a sua história de vida. O objectivo da entrevista era caracterizar as suas vivências desde a infância à idade adulta, procurando evidências de discriminação interseccional, quer no que respeita às diferentes fases do seu desenvolvimento, quer no que respeita à situação concreta do tráfico para fins de exploração sexual. A condução da entrevista, cuja duração foi de $1 \mathrm{~h} 30 \mathrm{~m}$, obedeceu às directrizes internacionais em matéria de boas práticas de atendimento a vítimas de tráfico de seres humanos ${ }^{3}$ e aos princípios da investigação feminista, nomeadamente o balanceamento de poder e a reflexividade (Neves \& Nogueira, 2004).

A entrevista foi gravada em áudio e posteriormente transcrita, respeitando-se e registando-se literalmente todos os aspectos do discurso. Para o seu tratamento usou-se o método de análise crítica do discurso, o qual permitiu a identificação de padrões de linguagem e a sua associação com práticas e representações sociais (Nogueira, 2001). A partir das categorias que foram emergindo da análise, foram efectuadas conexões entre temáticas, vivências, trajectórias e significados.

Serão apresentados excertos da entrevista de forma a ilustrar a análise efectuada.

\section{Resultados}

A Maria descreveu a sua infância como particularmente difícil, intitulando-a 'infelicidade'. As dificuldades económicas contribuíram, segundo a entrevistada, para a existência de um ambiente familiar pautado pelo conflito emocional, sendo a figura paterna especialmente problemática. Embora a família do pai fosse muito abastada, renegou-o pelo facto de ele ter decidido casar-se com a mãe dela. A violência física e psicológica do pai para com as

\footnotetext{
${ }^{3}$ Especialmente as expressas no International Organization for Migration Handbook on Direct Assistance for Victims of Trafficking (2007): respeito pela privacidade e confidencialidade, prevenção da re-vitimação, promoção da capacitação (empowerment), informação sobre os direitos.
} 
crianças e para com a esposa era uma constante, o que levou a Maria a desejar, desde muito cedo, ser independente:

"Ele sempre nos batia muito...batia em nossa mãe até sangrar (...). Eu chorava baixinho com medo dele (...) fazia de tudo para ele não me ouvir chorar...meus irmão apanhavam mais do que eu, eu era a caçula...meu pai dizia que eu era a sua menina. Mas me batia também. (...) Não tinha casa farta...era pobre, muito pobre (...). Queria ir embora para ser modelo".

O modelo educativo adoptado por esta família parecer ter sido caracterizado por uma evidente rigidez e inflexibilidade ao nível dos papéis de género. Rapazes e raparigas participavam apenas em actividades pretensamente adequadas ao seu sexo. Os rapazes ajudavam na roça e a Maria colaborava com a mãe nas lides domésticas. Este dado sobressai sobretudo a partir da adolescência de Maria, que ela apelida como triste. Por ser rapariga, foi remetida quase exclusivamente para a esfera familiar e doméstica, convivendo por isso muito pouco com outras raparigas ou com rapazes da sua idade em contextos não escolares. Lembra a escola como um espaço de liberdade e a casa como uma prisão. Nunca foi estimulada pela sua família para estudar:

"Vivia numa prisão...era um inferno a minha vida. Não saía, não ia a festas, não podia namorar...caçula e garota, já viu né? Mulher foi feita para estar em casa: era sempre o que minha mãe dizia. Eu tinha era que aprender a fazer marmita, lavar e passar. (...) Nós somos 9 irmãos, mas eu sou filha única, a única mulher, e por eu ser uma menina muito bonita, muito bonita mesmo, as pessoas me queriam para desfiles e essas coisas (...) ele (pai) tinha ciúmes de mim (...) ele sempre me acorrentava pela perna e me deixava trancada numa sala, né? (...) Para mim não sair de casa. (...) Meus irmãos faziam tudo e eu não fazia nada (...). Na escola eu era livre...aí namorava muito (...). (Altura da infância em que era mais feliz) Quando eu vinha da escola com os amigos e amigas, a gente vinha e ficava nos pés de manga a brincar, nas espigas de milho fazendo bonecas. Aquilo ali foi a melhor coisa da minha infância".

A relação da família de Maria (e da própria) com a igreja e com as suas práticas foi descrita como muito intensa, quer durante a sua infância, quer durante a adolescência. As questões da sexualidade eram tratadas como tabu pela família, sendo entendidas como pecado.

"Vivíamos rezando e na igreja. Meu pai era o que rezava mais (risos). Mas minha mãe também era muito crente. Todo o mundo tinha que ir na missa para pedir perdão a Deus. Eu pedia a Deus que me deixasse fugir e ser modelo".

A Maria foi vítima de abuso sexual pelo pai na adolescência. Decidiu casar para fugir à violência infligida pelo pai: 
"Com 13 anos fiquei assim esse mulherão...eu ia desfilar e ele ia lá para me buscar, me trazia pelos cabelos para casa, tava sempre a judiar de mim. Ele não queria que homem nenhum tocasse em mim (...). Um dia minha mãe viajou e ele pronto (hesitação)...minha mãe perguntou se eu queria ficar na casa de uma vizinha...eu tava lá, meus irmãos ficaram na casa da minha avó e ele me pegou e queria ter relação sexual comigo e eu falei para ele que se ele me obrigasse eu espetava uma faca em mim e deixava uma carta lá. Ele se masturbou na minha frente... deixei de ter pai nesse dia. Ele não me deixava dormir de noite, pegava nos meus seios, pegava nas minhas partes íntimas e ninguém acreditava em mim. Eu tinha um irmão e pedi que vigiasse eu, mas não adiantou (...). Eu casei muito nova para fugir dele (do pai)"”.

Para Maria, a sua idade adulta, a que chamava sofrimento, começou com o casamento. A experiência conjugal foi, ao contrário do que imaginava, muito negativa. Apesar de, na fase inicial, o marido a tratar bem, a relação foi-se deteriorando progressivamente, culminando no divórcio:

"Então no começo ele me tratava muito bem. Era como sabe, todos os homens (risos), que no começo era flores, depois começa (...) Ele tinha ciúmes de mim e começou a sair com outras mulheres. Me traía muito e me xingava. Eu gostava muito dele mas não dava para levar aquela vida".

O divórcio favoreceu o envolvimento na situação de tráfico para fins de exploração sexual. Não querendo voltar para casa dos pais, Maria viu na proposta de migração uma oportunidade para se autonomizar financeiramente. Foi aliciada por um indivíduo de nacionalidade brasileira, que era conhecido na região por recrutar mulheres jovens para viajar para Portugal, com a promessa de trabalho e dignificação das suas condições de vida. Foi este indivíduo quem lhe comprou a passagem aérea e lhe emprestou dinheiro, resultando daí uma dívida que teria que pagar quando instalada em Portugal. Maria nunca tinha estado envolvida anteriormente em actividades afectas à indústria do sexo e viajou para Portugal com a indicação de que iria trabalhar como auxiliar numa clínica médica. No seu caso, o projecto de emigração teve uma motivação estritamente económica, pretendendo regressar ao Brasil uma vez amealhado algum dinheiro:

"Eu queria trabalhar, ganhar o meu dinheiro, sabe? Para chegar lá no Brasil e ter alguma coisa para mim mais digna. Eu vim para cá inocentemente, eu me sentia muito humilhada na casa da minha família e aí encontrei essa pessoa que disse que ia me dar um emprego numa clínica, ou de pessoas idosas, e que eu ia conseguir os meus objectivos. Era tudo mentira. Aí me colocaram dentro da prostituição".

Contra a sua vontade, Maria foi obrigada a prostituir-se em casas de alterne da zona norte do país. Relatou várias histórias de violência e de discriminação, sobretudo pelo facto de ser brasileira: 
“Ter que suportar aqueles homens...você não tem noção do que é você ter que ir para a cama com um homem que você nunca viu por dinheiro. Nojentos, asquerosos. (...) eu não sei como muitas conseguem, eu não consigo. (...) Fiquei doente de parar no hospital, passei necessidades. (...) Ele (o gerente da casa) me pediu dinheiro e aí, como não tinha, ele pegou e me bateu muito, muito mesmo. Ele disse que me matava e fiquei com medo. Fiquei toda machucada e ele disse que no dia seguinte eu ia trabalhar do mesmo jeito. (...) Ele me obrigou a cortar meu cabelo que era grande, acima do quadril. Nunca tinha cortado o cabelo na minha vida porque a minha religião não permite e ele me obrigou a usar lentes. Ele disse que eu parecia uma cigana. Foi a coisa mais difícil da minha vida. Sou brasileira, não sou cigana. Mas brasileira parece que atrai”.

Neste historial de violência destaca-se igualmente a obrigatoriedade de pagar a dívida que havia contraído no Brasil com as despesas da passagem e outras:

"A dívida não acabava mais. O dinheiro que ganhava com os clientes era sempre pouco e nunca chegava (apontando para o caderno onde registava tudo). Depois havia as multas. Se não transava com os clientes que ele queria, multa, se estava menstruada, multa, se engordava, multa...nunca mais acabavam as multas".

A Maria mencionou sentir-se discriminada também pelas mulheres portuguesas que, segundo ela, a vêem invariavelmente como uma prostituta. O estigma parece acompanhar, na sua óptica, as mulheres brasileiras em geral, que são acusadas de vir para Portugal roubar os maridos às portuguesas.

$\mathrm{Na}$ altura em que a entrevista foi realizada, Maria encontrava-se sob protecção do SEF, depois de ter sido desmantelada a rede de tráfico na qual estava envolvida. Procurava retomar a sua vida, longe da prostituição, esperando regressar ao Brasil quanto antes para recomeçar a vida que sentia ter sido interrompida. Maria designou o seu futuro como vitória, acreditando que iria ser capaz de concretizar todos os seus objectivos: constituir família e ter uma casa.

\section{Discussão dos resultados/Conclusões}

Este estudo de caso aponta, de modo claro, para a necessidade de se analisar e compreender o fenómeno do tráfico de mulheres brasileiras para fins de exploração sexual a partir de uma grelha teórica interseccional. Como já tivemos ocasião de mencionar, as mulheres migrantes são particularmente vulneráveis à discriminação interseccional (Crenshaw, 1991), na medida em 
que são afectadas pelas suas múltiplas pertenças identitárias, encerrando estas o somatório de diferentes formas de opressão.

É nesta investigação bem evidente a forma como se intersectam essas múltiplas pertenças identitárias. A interacção entre as pertenças etária, de género, de nacionalidade e de classe parece ter potenciado a exposição de Maria a diferentes modalidades de discriminação e de violência, as quais, por sua vez, parecem ter favorecido o seu envolvimento na situação concreta de tráfico para fins de exploração sexual.

A precariedade socioeconómica que caracteriza o seu contexto de origem, Goiás (e que de acordo com a PESTRAF é o local de onde provém a maioria das mulheres brasileiras traficadas), terá limitado as suas oportunidades de autonomização, a par do modelo patriarcal em torno do qual a sua educação familiar foi sustentada. A rigidez e inflexibilidade no que respeita às práticas e aos discursos de género, terá acentuado a desigualdade de género no seio familiar (nomeadamente entre a Maria e os seus irmãos rapazes, mas também entre o pai e a mãe), revelando-se essa desigualdade na separação entre os espaços público e privado (sendo a Maria e a mãe confinadas ao espaço privado) e na violência física e emocional perpetrada pelo pai quer sobre os filhos, quer sobre a esposa. De realçar ainda o facto deste modelo patriarcal favorecer a legitimação da violência sexual que os pais homens exercem sobre as suas filhas mulheres, sendo estas encaradas como propriedade dos patriarcas. Como recordam Narvaz e Koller, em 2006,

“A história da instituição familiar, no Brasil, tem como ponto de partida o modelo patriarcal, importado pela colonização e adaptado às condições sociais do Brasil de então, latifundiário e escravagista. $\mathrm{O}$ patriarca era o detentor das posses, não apenas de seu latifúndio, mas de sua família, de seus agregados e escravos (p. 397).

Como pudemos constatar, Maria foi cronicamente vítima de abuso por parte do pai. A adesão a valores religiosos muito tradicionais impedia a família de abordar e discutir questões relacionadas com a sexualidade, sendo os comportamentos sexuais (com estranhos) antes do casamento reprovados. Esta cultura tabu não só contribuía para a manutenção do silêncio face ao abuso, como visava associar a sexualidade ao pecado, restringindo-a.

Embora a escola tivesse sido um contexto marcante na vida de Maria, permitindo-lhe experimentar a liberdade que não conhecia, não constituiu um efectivo factor de compensação na vida desta jovem. A interrupção do seu percurso escolar quando frequentava o $9 .^{\circ}$ ano, motivada pelo desejo de ser modelo e pela vontade de casar cedo para abandonar a família (o pai especialmente), terá limitado certamente os seus recursos para fazer face às dificuldades económicas que enfrentava. Os empregos de Maria sempre foram indiferenciados e instáveis, pelo que nunca chegou a adquirir inde- 
pendência financeira. O casamento com um homem mais velho, que ela própria designou como precoce, não se constituiu todavia como a melhor solução para os seus problemas, já que a relação com o marido foi igualmente marcada pela violência. Assim, o casamento pôs termo à violência sexual infligida pelo pai, mas não à violência psicológica, desta feita exercida pelo marido.

O divórcio, a resistência em voltar a casa dos pais, a necessidade de subsistir, as dificuldades económicas e o sentimento instalado de desânimo aprendido constituíram-se como factores de repulsão, promotores da decisão de imigrar. A promessa de um futuro condigno em Portugal, a proximidade com a língua e com a cultura, o conhecimento de outros casos de sucesso, funcionaram como factores de atracção no caso de Maria. A conjugação destes factores de repulsão e de atracção concorreu para a escolha de Portugal como destino migratório e para o seu envolvimento involuntário numa rede de tráfico de seres humanos. O perfil de Maria coadunava-se, pois, com o perfil de uma potencial vítima de tráfico para fins de exploração sexual: mulher estrangeira, jovem, bonita e oriunda de um país com nítidos contrastes sociais, onde as taxas de pobreza e de precariedade social são muito elevadas (económica e socialmente vulnerável portanto).

Defraudando todas as suas expectativas, a emigração intensificou as suas condições de vulnerabilidade social. Inserida na indústria do sexo contra a sua vontade, Maria foi confrontada com experiências de discriminação étnico-cultural e com episódios de violência severa (física, psicológica, sexual e social). De acordo com a própria, o facto de ser brasileira agravou a discriminação e a violência, uma vez que sobre as mulheres brasileiras recai o estigma da prostituição (independentemente de serem ou não prostitutas). Este dado vai ao encontro do que está documentado na literatura sobre os estereótipos construídos em torno das mulheres brasileiras, fruto de representações sociais assentes na ideia de uma sexualidade erotizada (Piscitelli, 2008; França, 2010) que coisifica as migrantes (Machado, 2005) e as despersonaliza. A manutenção dos estereótipos não só contribui para a invisibilidade da violência e da discriminação, como priva as mulheres brasileiras migrantes da protecção legal e social a que têm direito.

A história de vida de Maria é um exemplo entre muitos de uma mulher que é enredada numa teia de discriminação interseccional, que nos parece ser, acima de tudo, estrutural. A vulnerabilidade de Maria, ou de outras vítimas de tráfico para fins de exploração sexual, não é intrínseca, mas socialmente determinada. A vulnerabilidade destas mulheres é o produto de forças políticas, económicas e culturais que actuam em vários eixos das suas identidades e que as fragilizam nas suas opções e escolhas. 


\section{Referências}

Banda, F., \& Chinkin, C. (2004). Gender, minorities and indigenous peoples. Minority Rights Group International. Retrieved from http://www.psicologinelmondo.org/pdf/minorityrights-aug2004.pdf

Berger, M., \& Guidroz, K. (2009). Introduction. In M. Berger \& K. Guidroz (Eds.), The intersectional approach: Transforming academy through race, class and gender (pp. 1-22). Durham NC: The University of North Carolina Press.

Brooks, W., \& Redlin, M. (2009). Occupational aspirations, rural to urban migration, and intersectionality: A comparison of White, Black, and Hispanic male and female group chances for leaving rural counties. Southern Rural Sociology, 24(1), 130-152.

Butler, J. (1990). Gender trouble. London: Routledge.

Carling, J. (2006). Migration, human smuggling and trafficking from Nigeria to Europe. Oslo: International Organization for Migration.

Castles, S., \& Miller, M. (2003). The age of migration: International population movements in the modern world. Basingstoke, Nova Iorque, Macmillan.

Cavalcanti, V. (n.d.). Tráfico de pessoas, políticas públicas e o $4^{\circ}$ poder: Migrações que revelam vulnerabilidade e invisibilidade da condição feminina. Brasil: Universidade Católica do Salvador.

Collins, P. (2005). Black sexual politics: African-Americans, gender, and the new racism. New York: Routledge

Conselho de Europa (2005). Council of Europe Convention on Action against Trafficking in Human Beings. Retirado de http://www.coe.int/t/dg2/ trafficking/campaign/Source/PDF_Conv_197_Trafficking_E.pdf

Crenshaw, K. (1991). Mapping the margins: Intersectionality, identity, politics and violence against women of color. Stanford Law Review. 43, 1241-99.

Crenshaw, K. (2002). Documento para o encontro de especialistas em aspectos da discriminação social relativos ao género. Revista dos Estudos Feministas. 10(1), 171-188.

França, T. (2010). Alternando entre o trabalho e o prazer: Considerações de uma doutoranda brasileira. O Cabo dos Trabalhos: Revista Electrónica dos Programas de Mestrado e Doutoramento do CES/ FEUC/ FLUC. 4, 1-12. Retirado de http://cabodostrabalhos/ces.uc.pt/n4/ensaios.php

Global Alliance Against Traffic in Women (2000). Human Rights and Trafficking in Persons: A Handbook. Bangkok, Thailand: Global Alliance Against Traffic in Women.

Guerra, I. (2006). Pesquisa qualitativa e análise de conteúdo. Sentidos e formas de uso. Estoril: Princípia.

Hondagneu-Sotelo, P. (2005). Gendering migration: Not for "feminists only" - and not only in the household. The Center for Migration and Development: Princeton University. Retrieved from http://cmd.princeton.edu/papers/wp0502f.pdf 
International Organization for Migration (2007). The IOM Handbook on Direct Assistance for Victims of Trafficking. Geneva: International Organization for Migration.

Langevin, L., \& Belleau, M. (2000). Trafficking in women in Canada: A critical analysis of the legal framework governing immigrant live-in caregivers and mail-order brides. Ontario: Status of Women Canada.

Leal, M., \& Leal, M. (2005). Tráfico de mulheres, crianças e adolescentes para fins de exploração sexual comercial: Um fenômeno transnacional. Lisboa: SOCIUS - Centro de Investigação em Sociologia Económica e das Organizações. Retirado de http://pascal.iseg.utl.pt/ socius/publicacoes/wp/wp200504.pdf

Machado, I. (2005). Implicações da imigração estimulada por redes ilegais de aliciamento - O caso dos Brasileiros em Portugal. Lisboa: SOCIUS - Centro de Investigação em Sociologia Económica e das Organizações. Retirado de http://pascal.iseg.utl.pt/ socius/publicacoes/wp/wp200503.pdf

Ministério da Administração Interna (2009). Relatório Anual sobre Tráfico de Seres Humanos. Retirado de http://www.otsh.mai.gov.pt/cms/files/conteudos/ Manual_portugues.pdf

Moghadam, V. M. (1999). Gender and globalization: Female labor and women's mobilization. Journal of World-Systems Research. 2, 367-388.

Miko, F. (2003). Trafficking in women and children: The U.S. and international response. In A. Troubnikoff (Ed.), Trafficking in women and children: Current issues and developments (pp. 1-25). New York: Nova Science Publishers.

Miranda, J. (2009). Mulheres imigrantes em Portugal. Memórias, dificuldades de integração e projectos de vida. Lisboa: CEMRI.

Narvaz, M., \& Koller, S. (2006). A concepção de família de uma mulher-mãe de vítimas de incesto. Psicologia Reflexão e Crítica. 19(3), 395-406. DOI: 10.1590/S0102-79722006000300008.

Neves, S. (2010). Sonhos traficados (escravaturas modernas?): Tráfico de mulheres para fins de exploração sexual em Portugal. In S. Neves \& M. Fávero (Coords.), Vitimologia: Ciência e activismo (pp. 195-226). Coimbra: Almedina.

Neves, S., \& Nogueira, C. (2004). Metodologias feministas na psicologia social crítica: A ciência ao serviço da mudança social. Ex-Aequo: Revista da Associação Portuguesa de Estudos sobre as Mulheres, 11, 122-138.

Nogueira, C. (2001) A análise do discurso. In L. Almeida \& E. Fernandes (Coords.), Métodos e técnicas de avaliação: Novos contributos para a prática e investigação (pp. 15-48). Braga: CEEP.

Nogueira, C. (no prelo). Introdução à teoria da interseccionalidade nos estudos de género. In S. Neves (Coord.), Género e ciências sociais. Castêlo da Maia: Edições ISMAI.

Nolin, C. (2006). Transnational ruptures: Gender and forced migration. Aldershot: Ashgate.

McKee, J. O. (2000). Introduction. In J. O. McKee (Ed.), Ethnicity in contemporary America: A geographical appraisal (pp. 3-18). Boulder, CO: Rowman \& Littlefield. 
Padilla, B. (2006). Redes sociales de los brasileros recién llegados a Portugal: Solidaridad étnica o empatía étnica?. Revista Alternativas. Cuadernos de Trabajo Social, 14, 49-61.

Peixoto, J., Soares, A., Costa, P., Murteira, S., Pereira, S., \& Sabino, C. (2005). O tráfico de migrantes em Portugal: Perspectivas sociológicas, jurídicas e política. Lisboa: ACIME/Observatório da Imigração.

Piscitelli, A. (2004). On gringos and natives, gender and sexuality in the context of international sex tourism. Vibrant - Virtual Brazilian Anthropology, 1, 87-114. Retrieved form http://www.vibrant.org.br/portugues/artigos2004.htm

Piscitelli, A. (2007). Brasileiras na indústria transnacional do sexo. Nuevo Mundo-Mundos Nuevos, 7, 20.

Piscitelli, A. (2008). Interseccionalidades, categorias de articulação e experiências de migrantes brasileiras. Sociedade e cultura, 11(2), 263-274.

Pittaway, E., \& Bartolomei, L. (2001). Refugees, race, and gender: The multiple discrimination against refugee women. Xeno-Racism and International Migration, $19(6), 21-32$.

Raymond, J. (2002). Intersections between migration and trafficking. In J. Raymond (Coord.), Comparative study of women trafficked in the migration process. Patterns, profiles and health consequences of sexual exploitation in five countries (Indonesia, the Philippines, Thailand, Venezuela and the United States). (pp. 8-15). Coalition Against Trafficking in Women.

http://www.oas.org/atip/Migration/Comparativestudyofwomentraffickedinmigr ationprocess.pdf (January, 2009).

Santos, B., Gomes, C., Duarte, M., \& Baganha, M. I. (2007). Tráfico de mulheres em Portugal para fins de exploração sexual. Portugal. Projecto CAIM.

Santos, C. A. (2005). Mulheres imigrantes na imprensa Portuguesa. In SOS Racismo (Org.), Imigração e etnicidade - vivências e trajectórias de mulheres em Portugal (pp. 51-62). Lisboa: SOS Racismo

Schecter, T. (1998). Race, class, women and the state: The case of domestic labour. Montréal: Black Rose Books.

United Nations Development Programme (UNDP, 2006). Taking gender equality seriously. Making progress, meeting new challenges. New York: United Nations Development Programme. Retrieved form http://www.undp.org.pl/ publikacje/TakingGenderEqualitySeriously.pdf

VanWynsberghe, R., \& Khan, S. (2007). Redefining case study. International Journal of Qualitative Methods. 6(2). Retrieved from http://www.ualberta.ca/ $\sim$ iiqm/backissues/6_2/vanwynsberghe.pdf 